\title{
Musseques e favelas: devaneios da esperança
}

\author{
Oluemi Aparecido dos Santos ${ }^{1}$
}

RESUMO: O presente artigo tem como objetivo expor, à luz de Bachelard em seu A Poética do Espaço (1989), um breve estudo sobre a construção de imagens poéticas na obra dos poetas Solano Trindade (1908-1974) e Agostinho Neto (1922-1979), que tomam como espaço privilegiado de criação a favela e o musseque. Para tanto serão abordados textos de Sagrada Esperança (1979) de Neto e Cantares ao meu povo de Solano Trindade. Esperamos demonstrar como esses espaços contribuem na formação de imagens populares na obra dos dois poetas.

ABSTRACT: In accordance with The Poetics of Space, by Gaston Bachelard, this essay will discuss briefly about musseques and slums as places of artistic creation as represented in poetic works Sagrada Esperança (1979) by Agostinho Neto (1922-1979), and Cantares ao meu Povo (1961) by Solano Trindade (1908-1974). We intend to demonstrate how these spaces concur in the formation of popular images in those works.

PALAVRAS-CHAVE: Devaneio; devir; esperança; musseque; favela.

KEYWORDS: Reverie; devenir; hope; musseque; slums.

Ngendele ku museke, Uenzengue-uiu, mukatulaji kajú pó-pó-po, marimbondo ua-ngi-lumata. ${ }^{2}$

Ao analisar os espaços de nossas solidões, diz Gaston Bachelard que nossas lembranças têm refúgios cada vez mais característicos. A estes refúgios regressamos durante toda a vida e, para tal, conta-nos o autor que os devaneios são mais úteis do que os sonhos. Dentro dessa perspectiva, o espaço tem papel fundamental, pois o tempo já não mais anima a memória. Para Bachelard, é pelo espaço que podemos

\footnotetext{
${ }_{1}$ Mestrando em Estudos Comparados de Literaturas de Língua Portuguesa. FFLCH. USP. Bolsista FAPESP. Pesquisa: Sendas da Revolução: a poesia de Agostinho Neto e Solano Trindade. E-mail: oluemi@gmail.com

2 "Eu fui ao musseque numa chácara colher uns cajus, e os marimbondos me morderam" (folclore angolano).
} 
encontrar "os belos fósseis de duração concretizados por longas permanências. O inconsciente permanece nos locais” (1989, p. 29).

Assim, para o filósofo, "mais urgente que a determinação das datas é, para o conhecimento da intimidade, a localização nos espaços da nossa intimidade" (1989, p. 29).

Localizar alguns espaços da intimidade nas poesias do angolano Agostinho Neto (1922-1979) e do brasileiro Solano Trindade (19081974) é o que pretendemos estudar neste artigo.

Enfatizamos um elemento que, ao nosso ver, justifica a aproximação dos autores mencionados. Em 1958, Mário de Andrade, um dos maiores críticos literários de Angola, organiza e publica Antologia da Poesia Negra de Expressão Portuguesa. O crítico e organizador da antologia destaca em seu texto "Cultura Negro-africana e Assimilação" o fato de o debate sobre a cultura negro-africana ultrapassar as fronteiras de uma afirmação pura e simples dos valores negros ou, ainda, da contribuição desses valores para o enriquecimento de outras culturas, sendo que os intelectuais e escritores negros, no seu entender, situariam tais questões em outro plano e perspectiva que seriam os das: "a) relações entre o poder e a cultura, isto é, do condicionamento político das culturas negras; b) possibilidades duma renascença dos valores culturais negros e sua integração no patrimônio universal" (Andrade, 1958, p. VII-VIII).

Vale ressaltar que, tanto Agostinho Neto quanto Solano Trindade, trazem a marca de autores empenhados na luta pela emancipação e igualdade de direitos das populações mais sofridas e oprimidas. Ou seja, conscientes de seus papéis, pesa nestes dois poetas o ato de escrever como um movimento de insubordinação. Insubordinação esta contra as inúmeras barreiras que no curso da história estreitaram desde o início da colonização de Angola e Brasil as sendas da população negra, o que acabou também por limitar a ela as possibilidades da construção de sua identidade com inteireza, ou seja: homem, negro e angolano/brasileiro. Não por acaso, dentre os poetas que figuram na 
antologia, Solano Trindade foi o único poeta negro brasileiro escolhido por Mário de Andrade para compor a seleção.

Sagrada Esperança (1985) e Cantares ao meu povo (1961), respectivamente de Neto e de Trindade, são obras de referência dos dois autores e trazem quase que a totalidade de suas obras em poesia.

\section{Lembranças do lar}

Dentro do percurso proposto por Gaston Bachelard em A Poética do Espaço (1989), ateremo-nos particularmente às questões referentes à casa. Convém, porém antes, uma explicação: não tomaremos aqui a casa (o vocábulo) apenas em seu sentido mais estrito, ou seja, o espaço ou edificação no qual se mora. Logo, neste estudo ao nos referirmos á casa pensaremos nela tanto como sendo o espaço privado quanto como metáfora de musseques e favelas - espaço geográfico público - visto que nos estudos de Bachelard a própria dimensão da casa ultrapassa seus compartimentos indo além do espaço físico. Assim, nos diz Bachelard que "o complexo realidade-sonho nunca é definitivamente resolvido. (...) É preciso analisar melhor como se apresentam, na geometria do sonho, as casas do passado, as casas onde vamos reencontrar, em nossos devaneios, a intimidade do passado" (1989, p. 64). Entendemos que, para o estudo dos valores de intimidade do espaço interior, a casa é um "ser" privilegiado, desde que considerada ao mesmo tempo em sua unidade e complexidade, tentando integrar todos os seus valores particulares num valor fundamental.

Assim como há nas poesias de Neto um comprometimento com os musseques de Luanda, há também um registro das favelas da periferia brasileira bastante perceptível em Solano Trindade.

Ao transformar em suas poesias os espaços dos musseques e das favelas (em suma das periferias) em "seres" privilegiados Neto e Solano nos fazem percorrer essas sendas. Afinal, na aparente ingenuidade encontrada, seja "num banco do Kinaxixi", seja num "trem sujo da Leopoldina”, há um forte tom de crítica e insubordinação. 
Ainda que as favelas e os musseques sejam geralmente tomados pejorativamente como espaços de degradação, é aqui que os dois poetas se encontram e se sentem à vontade, "porque a casa é o nosso canto do mundo" (Bachelard, 1989, p. 24). Assim podemos entender o quanto é complexo determinar a realidade de nosso apego a um lugar predileto, um local que se identifica com a origem do ser.

Logo, não é de surpreender que os espaços geográficos privilegiados nas obras dos dois autores estejam recorrentemente relacionados com a periferia.

Diz Solano:

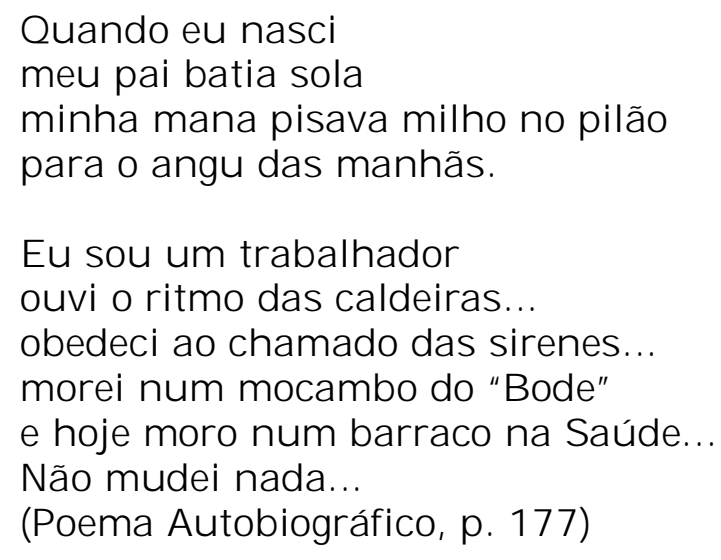

E Agostinho Neto:

Gostava de estar sentado num banco do Kinaxixi às seis horas duma tarde muito quente e ficar...

Alguém viria talvez sentar-se sentar-se ao meu lado

E veria as faces negras da gente a subir a calçada vagarosamente exprimindo ausência no kimbundo mestiço das conversas

Veria os passos fatigados dos servos de pais também servos buscando aqui amor ali glória além uma embriaguez em cada álcool 
Nem felicidade nem ódio

Depois do sol posto

acenderiam as luzes

e eu

iria sem rumo

a pensar que a nossa vida é simples afinal

demasiado simples

para quem está cansada e precisa de marchar.

(Kinaxixi, 1985, p. 48)

Podemos, juntos com os poetas, vivenciar os espaços vitais para eles. Tanto a casa privada, que, aliás, está localizada na periferia quanto o musseque. Podemos dizer que em tais espaços nossos poetas encontram "as dialéticas da vida, como nos enraizamos, dia a dia num canto do mundo" (Bachelard, 1989 p. 24).

"Porque a casa é o nosso canto do mundo. Ela é, como se diz amiúde, o nosso primeiro universo. É um verdadeiro cosmo" (ib.). E é desse cosmo - independentemente de como ele seja - que Neto e Trindade extraem também poesia.

Nos dois poemas, o centro da imagem e do devaneio é a nostalgia de um lugar querido. Os poemas oferecem imagens que nos fazem voltar ao tempo da infância, no primeiro caso, e ao de uma paz aparente, da tranqüilidade do musseque, no segundo texto.

Os escritores nos atraem para fontes de suas intimidades. A vida simples e sofrida de Solano não impede que, através de seu eu lírico, a primeira moradia seja abordada. O poema marca a passagem de vida rural para a urbana. Mesmo esse trânsito não retira do poeta a simplicidade e mesmo a ousadia de assumir suas origens.

Em "Kinaxixi”, temos um movimento semelhante de lembrança, visto que o eu lírico emprega logo no início do poema o verbo no pretérito imperfeito, enquanto que nos versos seguintes há uma predominância do futuro do pretérito. Recorrendo a dados extratextuais, verificamos que Neto deixara Angola para estudar medicina em Portugal. Mesmo assim, o espaço de intimidade que marca 
o poeta, e conseqüentemente o eu lírico, é justamente o Kinaxixi, o musseque.

Dessa forma, podemos dizer que os espaços realmente habitados são os que trazem a essência da casa bem como, deste nosso canto no mundo. Por isso não vemos, por exemplo, Copacabana ser exaltada na poesia de Solano ou Lisboa na de Neto. Em seu lugar, temos os espaços que abrigam de fato o devaneio, ou seja, o espaço da periferia. "O devaneio tem mesmo um privilégio de autovalorização. Ele usufrui diretamente de seu ser. Então, os lugares onde se viveu o devaneio reconstituem-se por si mesmos num novo devaneio. É exatamente porque as lembranças das antigas moradas são revividas como devaneios que as moradas do passado são imperecíveis dentro de nós” (Bachelard, 1989, p. 26)

Ao trazer à tona o Kinaxixi e o barraco na Saúde, os dois eus líricos revelam "concretamente os valores do espaço habitado, o não-eu que protege o eu” (ib., p. 24). Mais, "em suma, na mais interminável das dialéticas, o ser abrigado sensibiliza os limites do seu abrigo. Vive a casa em sua realidade e em sua virtude, através do pensamento e dos sonhos" (ib., p. 25)

Há nos dois poemas, é verdade, a nostalgia, mas há também o imperativo de mudança conferido pelo tom seco do poema de Solano e também pela angústia no eu lírico sujeito poético de Agostinho Neto devido à lentidão com que se marcha para a mudança. Em suma, as menções à pobreza e à submissão dos angolanos provocada pelo sistema colonial não são tomadas como uma nostalgia melancólica e sim como o ar da denúncia e da insubordinação, conforme já dissemos antes. Elementos externos ao poema nos ajudam a confirmar a impressão. No prefácio de Cantares, Solano Trindade revela:

Agradam-me profundamente os títulos de "poeta negro", "poeta do povo", "poeta popular", às vezes ditos de modo depreciativo mas que me dão uma consciência exata do meu papel de poeta na defesa das tradições culturais do meu povo, na luta por um mundo melhor. (1961, p. 25) 
Sobre o papel do escritor, defende Neto:

Todos nós, creio, que concordamos em que o escritor se deve situar na sua época e exercer a sua função de formador de consciência, que seja agente ativo de um aperfeiçoamento da humanidade. (...) Se temos de nos situar por um lado no fato independência e por outro no fato proletariado-campesinato, podemos perguntar-nos qual a posição do escritor diante do novo homem angolano, resultante da vitória histórica sobre um dos elementos da contradição colonial? (1978, p. 10-11)

Outros dois poemas que trazem de forma mais marcada a insubordinação e a denúncia são "Civilização Ocidental", de Neto, e "Civilização Branca", de Solano. Ao passo que as reminiscências em "Kinaxixi" e "Poema Autobiográfico", ainda que tristes, trazem também boas lembranças, nesses dois outros poemas lemos um tom muito mais agressivo.

O poema de Solano Trindade, curto e direto, refere-se a um espaço que é hostil à presença do homem negro: os arranha-céus, símbolos da sociedade burguesa, logo, brancos e ocidentais. Retirado do jornal (como não lembrar de Bandeira?), o poema espalha o clamor de um eu lírico que aparentemente apenas noticia o ocorrido. Contudo, o título aponta os responsáveis pelo crime que recai, sobretudo, na intolerância da camada dominante da sociedade:

\author{
LINCHARAM um homem \\ entre os arranha-céus \\ (li num jornal) \\ procurei o crime do homem \\ o crime não estava no homem \\ estava na cor de sua epiderme... (1961, p. 37)
}

Em "Civilização Ocidental", o espaço é ainda o dos musseques, mas o ultrapassa. À primeira vista, temos a imagem de um barraco de favela ou uma cubata. "Latas pregadas em paus fixados na terra fazem a casa". Mais adiante, vemos que se trata na verdade de um campo de contratados. Novamente encontramos a recusa dessa "civilização", que reserva após o trabalho forçado apenas a recompensa da morte. 
Latas pregadas em paus

fixados na terra

fazem a casa

Os farrapos completam

a paisagem intima

$\mathrm{O}$ sol atravessando as frestas

acorda o seu habitante

Depois das doze horas de trabalho

escravo

Britar pedra

acarretar pedra

britar pedra

acarretar pedra

ao sol

à chuva

britar pedra

acarretar pedra

A velhice vem cedo

Uma esteira nas noites escuras

basta para ele morrer

grato

e de fome. (1985, p. 31)

Fica evidente nos dois poemas as mazelas deixadas pela colonização e por um sistema opressor em relação ás chamadas minorias, mas isto não impede que musseques e favelas ocupem posição privilegiada na poesias dos dois poetas.

\section{Musseques e quilombos}

Antes de irmos ao próximo poema, vejamos mais uma perspectiva dada por Gaston Bachelard à casa e sobre a função de habitar. "Na vida do homem, a casa afasta contingências, multiplica seus conselhos de continuidade. Sem ela, o homem seria um ser disperso. Ela mantém o homem através das tempestades do céu e das tempestades da vida. É corpo e é alma. É o primeiro mundo do ser humano” (1989, p. 26).

Em “Canto aos Palmares” (Trindade, 1961, p. 29-35), desde que feitas algumas inferências, podemos ver retomada a questão da casa. Sem dúvida, o poema, que abre o livro, é um dos mais longos e 
enfáticos no combate à discriminação e injustiças. Seus versos são livres e brancos, com estrofes curtas e vibrantes, tendo o poema o tom épico.

Assim nos colocamos a pensar: qual a relação que pode ter esse poema com a questão da casa? Primeiro será preciso traçar uma dialética de pares opositivos: Lar vs. Cárcere, e Quilombo vs. Senzala.

Podemos assim perceber que lar e quilombo fazem parte de um paradigma, enquanto cárcere e senzala formam outro. É aí que podemos pousar nossa breve interpretação. É no devaneio de sua alma que o poeta encontra seu lar, é lá que se encontra com os seus (no quilombo), é lá que se sente protegido, lá é o seu refúgio. No quilombo, o poeta pode encontrar o "benefício mais precioso da casa", "a casa abriga o devaneio, a casa protege o sonhador, a casa permite sonhar em paz". (Bachelard, 1989, p. 26)

Em "Canto aos Palmares", a casa - o quilombo - estende-se e participa da luta de libertação, ela acaba por também aspirar à libertação. Referimo-nos neste momento a todo o espaço do quilombo, que assim como o eu lírico se revolta contra os opressores de todos os povos.

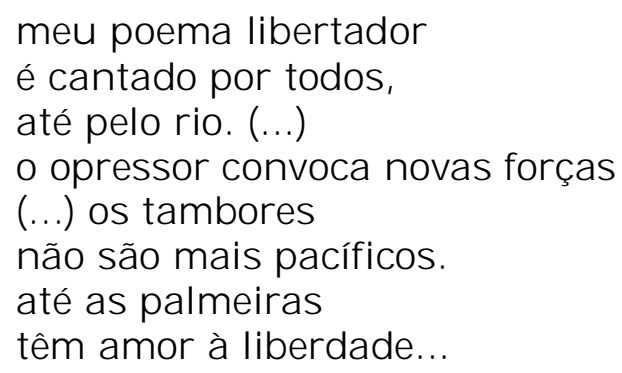

Num jogo de oposições, é mostrada a degradação da "civilização" em contrapartida com a materialização de um mundo mais humano no interior do quilombo. Como nos diz Benjamin Abdala Jr., essa degradação é mostrada "através de seus instrumentos de dominação (coloniais, neocoloniais, sociais), dentro da estratégia do confronto" (Abdala Jr., 2002, p. 37): 


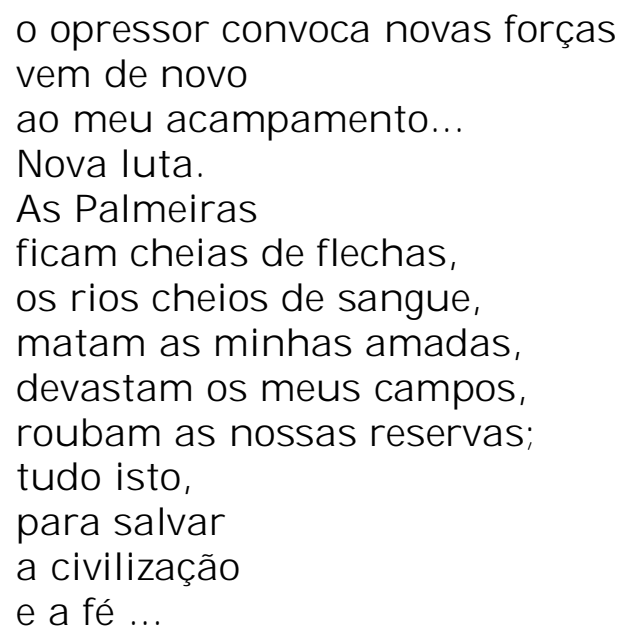

Contudo o eu lírico, juntamente com o espaço, se faz como centro de convergência, ator profético ou prometéico cantando a vitória:

\author{
Entre as palmeiras nascem \\ os frutos do amor \\ dos meus irmãos, \\ nos alimentamos do fruto da terra, \\ nenhum homem explora outro homem...
}

Vemos aí novamente a presença do espaço, do quilombo, da casa que abriga e dá possibilidades de sonhos aos seus. Observemos que um outro elemento de constituição do quilombo está bastante presente as palmeiras, como também possuem um lugar especial nas poesias de Agostinho Neto. Elas protegem, alimentam, assistem e colaboram na resistência, não por acaso essa árvore é tomada como símbolo pelos dois poetas. Peguemos apenas como exemplo o poema "O verde das palmeiras da minha mocidade" (Neto, 1985, p. 78), que traz várias lembranças ao poeta e revela a perda dos costumes angolanos por conta da nova "civilização" que se ergue em África. Vemos ainda, nos dois casos, que a aspiração de plenitude libertária se materializa e se fixa também no agora. O eu lírico, que "fugia do verde/ do verde-negro das palmeiras", agora vê que "o verde das palmeira/ tem beleza".

Vemos por conta das imagens até aqui exploradas que há uma verdadeira simbiose entre o ser e a casa nas imagens referidas. Como diz Bachelard, quanto mais atacado é o lar mais amado ele é, ou seja, 
ele se fortalece: "Nessa comunhão dinâmica entre o homem e a casa, nessa rivalidade dinâmica entre a casa e o universo, estamos longe de qualquer referência às simples formas geométricas. A casa vivida não é uma caixa inerte. O espaço habitado transcende o espaço geométrico" (1989, p. 62).

Assim a casa (quilombo), o ser e o poema sobrevivem sendo cantados ao longo dos séculos redimindo Zumbi e todos os ancestrais que deram suas vidas para se verem livres e humanizados.

Acreditamos que nesse poema, bem como em "O verde das palmeiras da minha mocidade", fica evidente a transformação do ser da casa em valores humanos, convidando o homem ao heroísmo.

\section{De novo o Musseque}

Tomando agora emprestado um poema de Agostinho Neto: "Sábado nos Musseques" (1979, p. 40), podemos explorar melhor o espaço em questão - a periferia - e registrar também a organicidade do espaço que dialoga com o homem. Como já foi referido antes, o musseque aparece constantemente nas poesias de Neto.

Aqui podemos também pensar em pares opositivos. O que está em cena não é mais a escravidão no novo continente, mas a cisão de mundos - o do colonizado e o do colonizador. A cidade alta e a cidade baixa, e é justamente nesta segunda que vai ser focalizado o olhar do poeta.

Dialético em sua essência, o musseque (caldo cultural efervescente onde tudo acontece e tudo se encontra) pode e deve também ser visto como espaço de resistência. Assim temos, em ambas as situações, a oposição entre o cárcere e a liberdade, tendo de um lado o colonizado e do outro o colonizador.

Também de grande fôlego, o poema agora em questão nos apresenta mais uma imagem "viva" do musseque do que um confronto propriamente dito, embora este esteja sempre presente. O poeta nos apresenta o musseque em suas "ansiedades", como um espaço vivo no 
qual a orquestração da vida segue por várias e diferentes notas; tendo, porém, um único regente - o próprio musseque.

É ele também, apesar de suas contradições, o local onde se sofre, luta, chora e também se colhe esperança, esperança ansiosa em ver renascer um novo homem, um novo mundo:

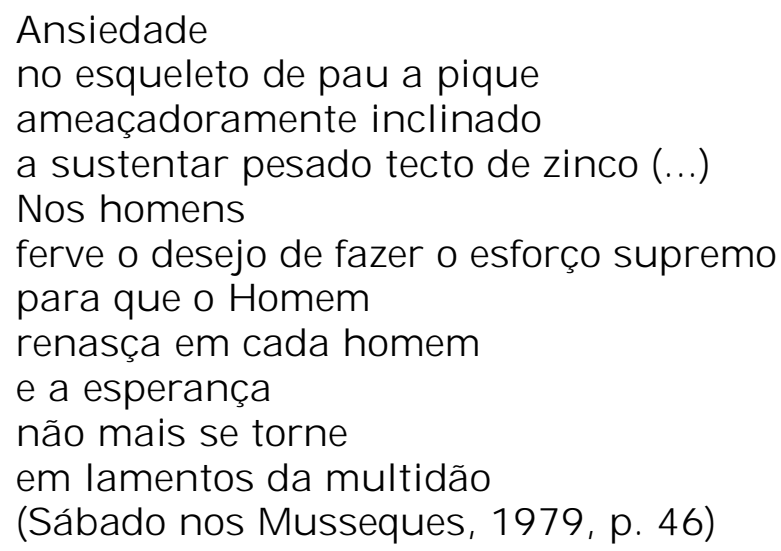

Nesse espaço "humilde" de "gente humilde", o sábado vem ao encontro da vida. A organicidade está presente em todo o musseque, ou seja, é o próprio musseque. Numa rasa analogia, se tomarmos como referência a resistência e também a opressão, podemos dizer que o musseque, assim como a favela, atualiza o espaço da senzala e do quilombo. Tanto nas cubatas quanto nos barracos, ambos "latas pregada em paus/ fixados na terra” (Neto, 1985, p. 31) temos imagens poéticas que revelam a resistência e os devaneios de esperança no devir.

\section{Vive a esperança}

Procuramos até aqui mostrar como a periferia (musseques e favelas) e também alguns outros espaços de opressão e resistência podem ser vistos como um espaço privilegiado nas poesias de Solano Trindade e Agostinho Neto. Para encerar nosso breve percurso, gostaríamos de examinar uma última poesia de Solano Trindade que sintetiza - acreditamos — os musseques e as favelas (e também a infância) como espaço de solidariedade que os poetas projetam no devir. Para tal escolhemos "Mulher Barriguda” (1961, p. 88): 
Mulher barriguda que vai ter menino

qual o destino

que ele vai ter?

que será ele

quando crescer?

Haverá guerra ainda?

tomara que não,

mulher barriguda

tomara que não...

Retomemos a questão da casa. Nos diz Bachelard (1989, p. 24) que "nossa vida adulta é tão despojada dos primeiros bens, os vínculos antropocósmicos são tão frouxos, que não sentimos sua primeira ligação com o universo da casa". Logo, não é difícil entender porque geralmente não consideramos nosso primeiro ninho, onde de fato começa a vida. E há uma primeira casa mais exemplar para nós que o útero materno? "A vida começa bem, começa fechada, protegida, agasalhada no regaço da casa" (1989, p. 26). Portanto, não é de surpreender que o poeta deposite seu olhar, sua esperança, no devir justamente na criança que vai nascer. É a partir dessas imagens populares que os nossos poetas projetam espaços da universalização e da solidariedade entre os homens e povos.

E assim, diante da "casa" que guarda a esperança, a crença no devir que finalizamos nosso breve percurso, salientando que não tivemos aqui a intenção de esgotar as questões levantadas. Esperamos ter conseguido demonstrar, ainda que minimamente, que musseques e favelas recebem especial atenção dentro das obras dos autores aqui mencionados, transformando-se não apenas em espaço de miséria, mas que, ao serem tomados como espaços da intimidade, esses espaços se tornam também em devaneios de esperança, nos quais podemos ainda sonhar com a "harmonia do mundo". 


\section{Referências bibliográficas}

ABDALA JR. Benjamin. "António Jacinto, José Craveirinha, Solano Trindade - O Sonho (Diurno) de uma Poética Popular". In: Via Atlântica. São Paulo: Departamento de Letras Clássicas e Vernáculas, 2002.

ANDRADE, Mario Pinto de. Antologia da Poesia Negra de Expressão Portuguesa. Paris: Pierre Jean Oswald, 1958.

BACHELARD, Gaston. A Poética do Espaço. São Paulo: Martins fontes, 1989.

CAMARGO, Oswaldo. de. (org.) A razão da chama: Antologia de Poetas Negros Brasileiros. São Paulo: Edições GRD, 1986.

- O Negro Escrito - Apontamentos sobre a presença do negro na Literatura Brasileira. São Paulo: Imprensa Oficial do Estado S/A IMESP, 1987.

COSME, Leonel. Agostinho Neto e o seu tempo. Porto: Campo das Letras, 2004.

LARANJEIRA, Pires. A negritude africana de língua portuguesa. Porto: Edições Afrontamento 1995.

NETO, Agostinho. Sobre a Literatura. Luanda: União dos Escritores Angolanos, 1978.

. Sagrada esperança. São Paulo: Ática, 1985.

TRINDADE, Solano. Cantares ao meu povo. São Paulo: Fulgor, 1961. 